\title{
Improvement of thermally formed nickel silicide by ion irradiation
}

\author{
L. S. Wieluński, ${ }^{\text {a) }}$ C-D. Lien, B. X. Liu, ${ }^{\text {b) }}$ and M-A. Nicolet \\ California Institute of Technology, Pasadena, California 91125
}

(Received 14 August 1981; accepted 14 September 1981)

\begin{abstract}
A significant improvement of the lateral uniformity of thermally formed $\mathrm{Ni}_{2} \mathrm{Si}$ layers has been observed after low-dose $\left(10^{13} \sim 3 \times 10^{14}\right.$ ion $\left./ \mathrm{cm}^{2}\right)$ Xe irradiation of an As-deposited Ni film. Measurements have also been made on samples that contained a thin impurity layer formed intentionally between the silicon substrate and the evaporated nickel film. The impurity layer was thick enough to prevent thermal silicide formation in unirradiated samples, but in irradiated samples, the silicide formation was not prevented. Similar results were obtained for As implantations. We attribute this effect to ion mixing of the interfacial layer. These results demonstrate that a low-dose irradiation can render the process of silicide formation by thermal annealing more tolerant to interfacial impurities. The concept is of potential significance to VLSI technology.
\end{abstract}

PACS numbers: $68.48 .+\mathrm{f}, 68.55 .+\mathrm{b}, 85.40 .-\mathrm{e}, 81.80 . \mathrm{Bn}$

\section{INTRODUCTION}

Metal silicide films are widely used for Schottky barriers and ohmic contacts in Si devices. As the trend toward VLSI technology reduces the lateral and depth dimensions of metal and metal silicide layers, it becomes desirable as well to lower the processing temperatures for the silicide formation. The cleanliness of the metal-silicon interface then becomes a very important consideration and a difficult part of the technology. The growth of laterally nonuniform silicides is a typical result of residual contamination at the metal-silicon interface upon low-temperature annealing.

In this paper, we report that low-dose ion irradiation leads to a significant improvement of the lateral uniformity of thin $\mathrm{Ni}_{2} \mathrm{Si}$ layers formed thermally at $250^{\circ} \mathrm{C}$. We show that ion irradiation leads to the formation of laterally uniform $\mathrm{Ni}_{2} \mathrm{Si}$ layers even in the case of intentionally formed interfacial impurity layers.

\section{EXPERIMENTAL PROCEDURES}

Samples used in this work were prepared from commercially offered $\langle 100\rangle \mathrm{Si}$ wafers. Three standard cleaning procedures were applied:process I consisted of organic cleaning only (first with acetone, and second with methanol, in an ultrasonic bath). Process II consisted of organic cleaning as in process $\mathrm{I}$, followed by etching in $12 \% \mathrm{HF}$ and then oxidation in RCA solution $\left(\mathrm{H}_{2} \mathrm{O}_{2}+\mathrm{NH}_{4} \mathrm{OH}+\mathrm{H}_{2} \mathrm{O}\right)$. Process III was the same as process II, but followed by etching in an aqueous $3 \% \mathrm{HF}$ solution.

After process I, silicon wafers are covered by silicon oxide formed at room temperature during storage. Process II leaves the silicon wafers covered by an oxide formed in the last step of this procedure. ${ }^{1}$ Process III gives quite a clean silicon surface which, however, contains much more fluorine than after process I or II.'

Immediately after preparation, the wafers were loaded into an oil-free e-beam evaporation system. Nickel films of
300 and $500 \AA$ thickness were evaporated at $20 \AA / \mathrm{s}$ with vacuum kept below $3 \times 10^{-7}$ Torr during evaporation. The samples were then implanted with $300 \mathrm{keV} \mathrm{Xe}^{+}$ions at room temperature or $175^{\circ} \mathrm{C}$. The range of $\mathrm{Xe}$ ions in $\mathrm{Ni}$ is $R_{p} \approx 380 \AA$ and the range straggling is $\Delta R_{p} \approx 190 \AA \AA^{2}$ The irradiations were performed with doses of $3 \times 10^{13}, 1 \times 10^{14}$, $3 \times 10^{14}$, and $1 \times 10^{15} \mathrm{~cm}^{-2}$.

The direct effect of the irradiation was monitored by $\mathrm{He}^{+}$ backscattering spectrometry (BS). The analyzing He beam was incident at $70^{\circ}$ with respect to the normal of the sample surface. The detector was positioned at an angle $170^{\circ}$ against the incident beam direction in the plane defined by the incident beam and the tilt axis of the sample.

Afterwards, samples were loaded into a quartz tube furnace for vacuum annealing and thermal silicide formation. The $500 \AA$ Ni layers were annealed at $250^{\circ} \mathrm{C}$ for $20 \mathrm{~min}$; the $300 \AA \mathrm{A} \mathrm{Ni}$ layers were annealed $240^{\circ} \mathrm{C}$ for $20 \mathrm{~min}$. The residual pressure during annealing was kept below $2 \times 10^{-6}$ Torr. Thickness and lateral uniformity of the silicides formed were monitored by repeated BS analyses. Identical procedures were followed for samples irradiated with $182 \mathrm{keV} \mathrm{As}^{+}$ions instead of $\mathrm{Xe}^{+}$. The range of $182 \mathrm{keV} \mathrm{As}^{+}$in $\mathrm{Ni}$ about equals that of $300 \mathrm{keV} \mathrm{Xe}{ }^{+}$ions. ${ }^{2}$ The impurities contaminating the interface have been measured on as-deposited samples by SIMS. ${ }^{16} \mathrm{O},{ }^{19} \mathrm{~F},{ }^{12} \mathrm{C}$, and ${ }^{29} \mathrm{Si}$ signals were monitored. The ${ }^{16} \mathrm{O}$ signal is about seven times higher after process II than after process III. However, the ${ }^{19} \mathrm{~F}$ and ${ }^{12} \mathrm{C}$ contamination after process II is lower than after process IIIthree and five times, respectively.

\section{RESULTS}

A direct effect of ion mixing without post annealing is visible only in BS spectra of samples irradiated with the highest doses of $1 \times 10^{15} \mathrm{Xe}$ ions $/ \mathrm{cm}^{2}$. For doses lower than that, the BS spectra were indistinguishable from the spectra of unimplanted samples. However, spectra taken after thermal 


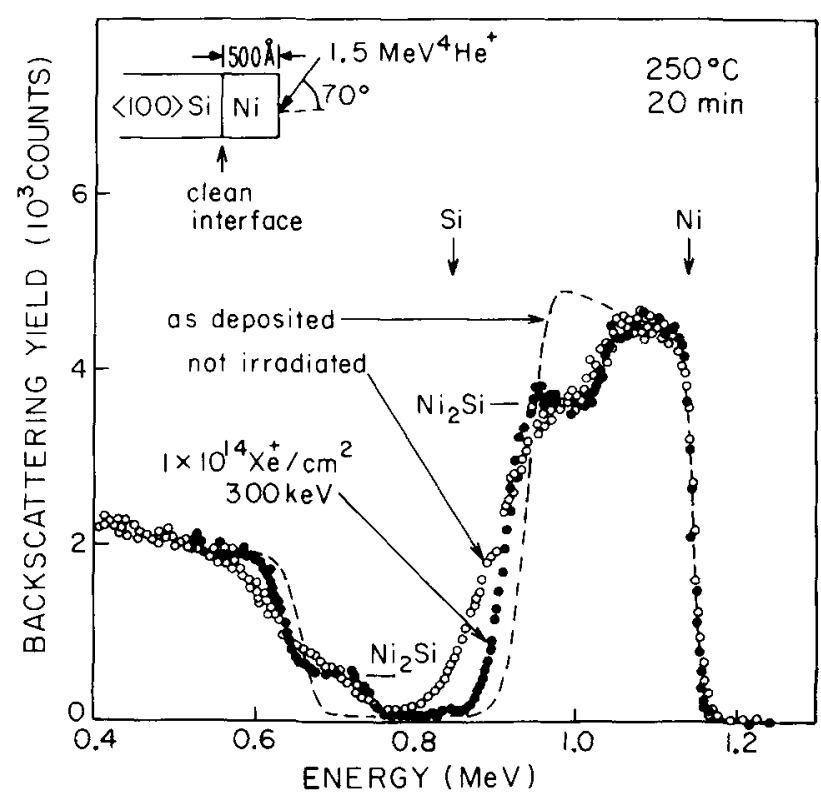

FiG. 1. Backscattering spectra of a 500-A Ni film deposited on clean silicon (cleaning process III). Dashed line: as-deposited sample; open circles: sample annealed as is for $20 \mathrm{~min}$ at $250^{\circ} \mathrm{C}$; full circles: sample annealed for 20 min at $250^{\circ} \mathrm{C}$ after $300 \mathrm{keV} \mathrm{Xe}^{+}$room temperature irradiation with $10^{14}$ $\mathrm{Xe}^{+} / \mathrm{cm}^{2}$.

annealing show significant effects due to the low-dose irradiation. Figure 1 compares spectra measured for annealed samples irradiated with $1 \times 10^{14} \mathrm{Xe}$ ions $/ \mathrm{cm}^{2}$, and unirradiated samples, with $500 \AA \mathrm{Ni}$ films deposited on a clean $\mathrm{Si}$ substrate (cleaning process III). The dashed line is the spectrum for the as-deposited sample. The irradiated unannealed sample had essentially the same spectrum as the as-deposited sample.

After annealing, the BS spectra indicate that the irradiated sample has formed a layer of thermally formed silicide that is more uniform than the silicide layer of the unirradiated sample. This fact is seen most clearly in the difference of the low energy edges of the Ni signals. The spectrum of the irradiated sample has a sharper edge than the unirradiated sample. The ratio of the $\mathrm{Ni}$ and $\mathrm{Si}$ signal heights for the silicide layers corresponds to stoichiometric $\mathrm{Ni}_{2} \mathrm{Si}$ in both samples. Formation of this compound has been confirmed by $x$-ray diffraction (Read camera) measurements.

A similar improvement of lateral uniformity has been observed for samples irradiated with doses of $1 / 3$ and $3 \times 10^{14}$ $\mathrm{Xe}$ ions $/ \mathrm{cm}^{2}$. In the case of the thin $(300 \AA) \mathrm{Ni}$ layer, a similar effect was also obtained, however, for the same Xe energy, the same outcome is observed at irradiation doses that are lower than those required for $500 \AA \mathrm{Ni}$ samples.

Identical measurements were made for samples with an intentionally contaminated interface between the Si substrate and the Ni film (cleaning process II). Figure 2 shows spectra obtained for irradiated and unirradiated samples after annealing. The presence of an impurity layer prevents the Ni silicide formation in an unirradiated sample. In the irradiated one, we observe a silicide formation similar to that seen in the clean sample, if the implantation dose reaches the level of $3 \times 10^{14} \mathrm{Xe}$ ions $/ \mathrm{cm}^{2}$ for $500 \AA$ of the Ni film. The

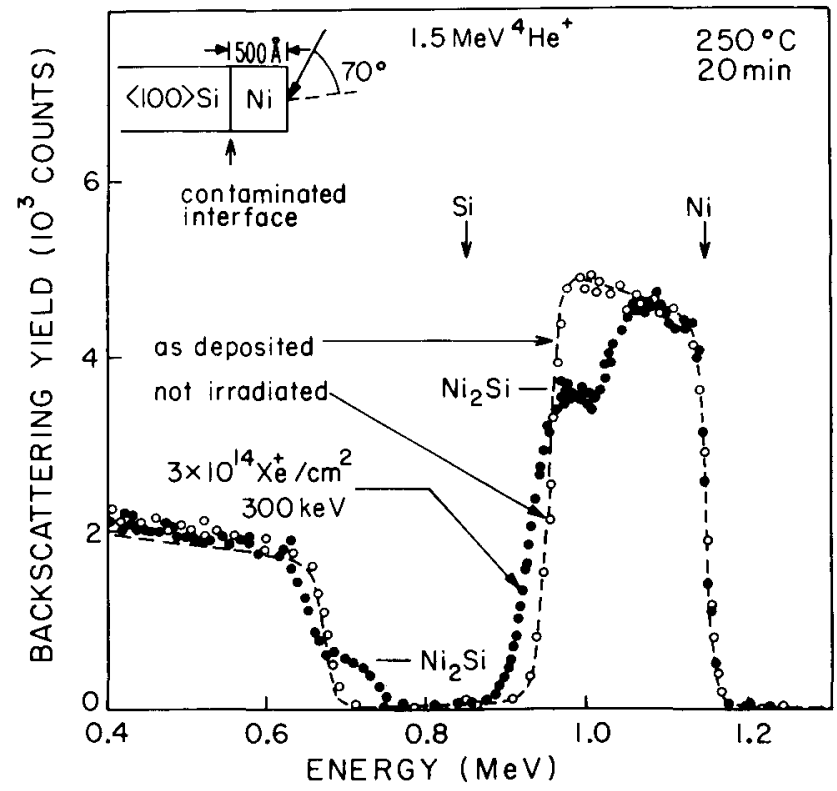

FIG. 2. Backscattering spectra of a $500-\AA ̊ \mathrm{Ni}$ film deposited on silicon with intentionally formed interfacial layer (cleaning process II). Dashed line: asdeposited sample; open circles: sample annealed as is for $20 \mathrm{~min}$ at $250^{\circ} \mathrm{C}$; full circles: sample annealed for $20 \mathrm{~min}$ at $250^{\circ} \mathrm{C}$ after $300 \mathrm{keV} \mathrm{Xe}^{+}$room temperature irradiaton with $3 \times 10^{14} \mathrm{Xe}^{+} / \mathrm{cm}^{2}$.

same result was also seen for samples with a thin $(300 \AA) \mathrm{Ni}$ film at irradiation doses of about $1 \times 10^{14} \mathrm{Xe}$ ions $/ \mathrm{cm}^{2}$. These results show that ion irradiation sustains the thermal reactivity of a $\mathrm{Ni}$ film on a Si substrate in the presence of a contaminated interface.

The same experiment has been performed with $500 \AA$ thick Ni films deposited on Si wafers that were only organically cleaned (cleaning process I). These results were very close to those just reported for intentionally contaminated samples formed by the cleaning process II. Xenon irradiations were also made both at room temperature and $175^{\circ} \mathrm{C}$. There were no significant differences in the results for these two cases.

We have repeated the experiment on samples with an intentionally formed interfacial impurity layer and with a clean interface using $182 \mathrm{keV} \mathrm{As}^{+}$ions for the irradiation, for both 300 and $500 \AA$ thick Ni layers. The results observed were as in the case of Xe irradiation. Figure 3 shows BS spectra obtained after annealing of a sample irradiated with $\mathrm{Xe}$ and As. The samples had (slightly different) Ni layer thickness of about $500 \AA$ each. In both cases, the same layer of $\mathrm{Ni}_{2} \mathrm{Si}$ is seen to form during thermal annealing.

Samples irradiated with $10^{15} \mathrm{Xe}$ ions $/ \mathrm{cm}^{2}$ show a visible ion mixing effect in BS spectra taken after exposure to the beam. These same samples, when measured after annealing at $250^{\circ} \mathrm{C}$, also show a formation of silicide, but the silicide layer is much thinner than that typically formed after annealing by samples irradiated to lower doses. Increasing the annealing time by a factor of 3 did not significantly increase the thickness of this layer. In the case of a contamination interface (cleaning processes I or II), the Ni to Si ratio in the silicide layer was $3: 2$. 


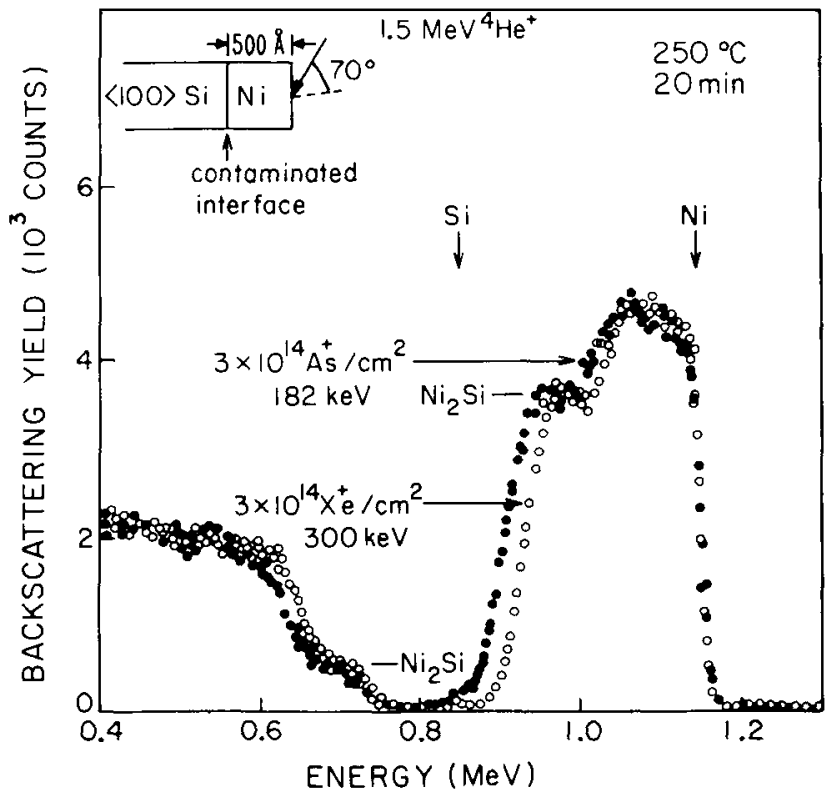

FIG. 3. Backscattering spectra of a $500-\AA$ A Ni film deposited on silicon with intentionally formed interfacial layer and irradiated at room temperature with a dose of $3 \times 10^{14} \mathrm{~cm}^{-2}$ before thermal annealing. Open circles: 300 $\mathrm{keV} \mathrm{Xe}{ }^{+}$irradiaton; full circles: $182 \mathrm{keV} \mathrm{As}^{+}$irradiation.

\section{DISCUSSION}

The experimental results presented above can be explained if we posit that the silicide formation process at low temperatures $\left(\leqslant 250^{\circ} \mathrm{C}\right)$ is sensitive to interfacial impurity layers. The silicon cleaning procedure applied in the sample preparation determines the thickness and composition of the interfacial layer. 'The cleanest interface is obtained with process III, which leaves much less interfacial oxygen and hydrogen than processes I or II do. ${ }^{1,4}$ However, even then the residual layer can locally slow down the silicide formation process and causes the observed lateral nonuniformity of the silicide. A silicide is not formed if the interfacial impurity is increased, as happens after the cleaning processes I or II.

The improved lateral uniformity or irradiated clean samples (cleaning process III) can be explained by a breakup of the interfacial layer by the incident ion. ${ }^{5,6}$ This effect is sufficiently efficient that even in the case of an intentionally produced impurity layer (cleaning processes I or II), a silicide forms after implantation with doses of $3 \times 10^{14} \mathrm{Xe} / \mathrm{cm}^{2}$. A comparison of the results for different thicknesses of the $\mathrm{Ni}$ layer ( 300 and $500 \AA$ ) suggest that the process is related to the energy density deposited in the interfacial region. For $300 \AA$ thick Ni films, the lateral uniformity and the sustained thermal reactivity induced by the irradiation are achieved at lower doses than for $500 \AA \mathrm{Ni}$ films. For $300 \AA \mathrm{Ni}$ films, the interfacial layer is located in the region where the density of energy deposited in nuclear processes reaches a maximum.

A different interpretation is to associate the improvement of the lateral uniformity to the radiation damage in the silicon single-crystal substrate. The structural defects contained in $\mathrm{Si}$ after irradiation are a strong function of the irradiation temperature. ${ }^{7}$ Our results for irradiation at room temperature and $175^{\circ} \mathrm{C}$ show an insignificant temperature dependence, but the difference in the irradiation temperature may not suffice to draw a definite conclusion. It would be interesting to have results for higher temperatures $\left(>300^{\circ} \mathrm{C}\right.$ ), but that is unavailing in the case of Ni because $\mathrm{Ni}_{2} \mathrm{Si}$ forms thermally at $250^{\circ} \mathrm{C}$.

Either interpretation is consistent with the observation that both $\mathrm{Xe}$ and $\mathrm{As}$ ions produce the effect. In fact, one would expect that the chemical identity of the irradiation ion would primarily affect only the required dose and energy. Silicon ions stand out as particularly attractive choice in application, because secondary impurity effects on the subsequent thermal reaction are thereby eliminated.

A recent study in the silicide formation of thin $\mathrm{Er}$ and $\mathrm{Tb}$ films shows that in those cases, samples with amorphous and single crystalline substrates exhibit the same changes in thermal reaction morphology upon irradiation. ${ }^{8}$ The investigators point out that the irradiation may disperse interfacial contaminations as a result of the atomic mixing process, which concurs with our findings. To close, we note that the same concept has been successfully applied to promote epi growth in the solid-phase of amorphous deposited Si layers on Si single-crystal substrates. ${ }^{9}$ It would clearly be of interest to know the effect of low-dose ion irradiation on the formation of other metal silicides. Such investigations with $\mathrm{Pt}$ and $\mathrm{Cr}$ are presently in progress.

\section{SUMMARY}

We have shown that $\mathrm{Xe}$ and As irradiation sustains the thermal reactivity of $\mathrm{Ni}$ films on $\mathrm{Si}$ substrates and improves the lateral uniformity of the reaction during annealing. For both ions, we observed that the silicide formation is slowed down when the ion dose reaches a value of $10^{15}$ ion $/ \mathrm{cm}^{2}$. This effect has been accompanied by formation of an unusual $\mathrm{Ni}_{3} \mathrm{Si}_{2}$ layer as measured by $\mathrm{BS}$ after cleaning process $\mathrm{I}$ or II. Similar effects have been observed with $\mathrm{O}$ or $\mathrm{N}$ implantation. ${ }^{10,11}$

Improvement of lateral uniformity of silicide and sustaining thermal reactivity even in an unclean interfacial condition can help in VLSI technology, where cleaning of very small windows becomes a serious technological problem.

\section{ACKNOWLEDGMENTS}

The authors thank C. A. Evans, Jr., and R. D. Blattner, of Charles Evans \& Associates, for the SIMS analysis of two samples to characterize the interfacial impurities. S. S. Lau, of the University of California at San Diego, contributed many helpful discussions; and G. B. Larrabee and S. Matteson, of Texas Instruments, encouraged us to proceed with this investigation. We gratefully acknowledge these contributions. The work was executed under the benevolent $\mathbf{U}$. R. Fund of the Böhmische Physical Society (B. M. Ullrich). The implantation aspect of this study was financially supported by the U. S. Department of Energy through an agreement with the National Aeronautics and Space Administration and monitored by the Jet Propulsion Laboratory, California Institute of Technology (D. Bickler).

${ }^{a)}$ Permanent Address: Institute of Nuclear Research, Warszawa, Hoza 69, Poland. 
b/Permanent Address: Qinghua University, Beijing, People's Republic of China.

${ }^{1}$ M. von Allmen, S. S. Lau, D. M. Scott, J. W. Mayer, W. F. Tseng, T. T. Sheng, P. Williams, and J. E. Baker, in Thin Film Interfaces and Interactions, edited by J. E. E. Baglin and J. M. Poate (Electrochemical Society, Princeton, 1980), Vol. 80-2, p. 195.

${ }^{2}$ These data have been obtained from tables in Ref. 3 by interpolation. ${ }^{3}$ B. Smith, Ion Implantation Range Data for Silicon and Germanium Device Technologies (Research Studies, Forest Grove, OR, 1977).

${ }^{4}$ L. S. Hung, S. S. Lau, M. von Allmen, J. W. Mayer, B. M. Ullrich, J. E. Baker, P. Williams, and W. F. Tseng, Appl. Phys. Lett. 37, 909 (1980).

${ }^{5}$ S. Matteson, B. M. Paine, M. G. Grimaldi, G. Mezey, and M-A. Nicolet, Nucl. Instrum. Methods 182/183, 43 (1981).
'J. W. Mayer, B. Y. Tsaur, S. S. Lau, and L. S. Hung, Nucl. Instrum. Methods 182/183, 1 (1981).

${ }^{7}$ J. W. Mayer, L. Eriksson, and J. A. Davies, Ion Implantation in Semiconductors, (Academic, New York, 1969), p. 150.

${ }^{8}$ B. Y. Tsaur and L. S. Hung, Appl. Phys. Lett. 37, 922 (1980).

${ }^{9}$ T. W. Sigmon and W. F. Tseng, in Thin Film Phenomena-Interfaces and Interactions, edited by J. E. E. Baglin and J. M. Poate (Electrochemical Society, Princeton, 1978), p. 99.

'D. M. Scott and M-A. Nicolet, Nucl. Instrum. Methods 182/183, 655 (1981).

"L. Wieluński, D. M. Scott, M.-A. Nicolet, and H. von Seefeld, Appl. Phys. Lett. 38, 106 (1981). 